\title{
Review
}

\section{Use of Microalgae for the Control of Luminous Vibriosis in Tropical Shrimp Aquaculture}

\author{
Christopher Marlowe A. Caipang** and Mary Paz N. Aguana \\ ${ }^{a}$ School of Applied Science, Temasek Polytechnic, Singapore - 529757 \\ ${ }^{b}$ Institute of Aquaculture, College of Fisheries and Ocean Sciences, University of the Philippines Visayas, \\ Miag-ao 5023, Iloilo, Philippines
}

(received April 21, 2014; revised June 23, 2014; accepted June 26, 2014)

\begin{abstract}
Outbreaks of luminous vibriosis in commercial shrimp ponds have been the major cause in the decline of shrimp production in most tropical countries. The causative agent of this disease is Vibrio harveyi, and is one of the many Vibrio species that affect Asian aquaculture. Efforts to prevent the occurrence of luminous vibriosis in shrimp ponds are largely based on the application of antibiotics in the ponds or inclusion of these compounds in the diets of the shrimp. However, indiscriminate use of these antimicrobial compounds results in more virulent and drug-resistant strains of the pathogen. The search for alternative strategies to control luminous vibriosis in the culture facilities led to the development of the so-called "green water" technology. This technology is an innovative technique in which the shrimp stock is cultured in water, where microalgae such as Chlorella sp., and other green microalgae grow abundantly. When this species of phytoplankton has abundant growth in the pond, the water assumes a green colouration, hence the term "green water". This paper discusses the advances on the use of this "green water" technology to inhibit luminous vibriosis in tropical shrimp aquaculture.
\end{abstract}

Keywords: aquaculture, luminous vibriosis, microalgae, shrimp, Vibrio harveyi, green water

\section{Introduction}

Aquaculture has developed rapidly over the last few decades to become an important global economic activity. Philippines is among the top four aquacultureproducing countries in the region, contributing about $2.5 \%$ of total global production (Tacon, 2003). Shrimp continues to be the main commodity traded in terms of value. The main cultivated species are the giant tiger prawn (Penaeus monodon), the fleshy prawn (P. chinensis), and the white leg shrimp (P. vannamei) (Tacon, 2003).

The Philippines has a long tradition of aquaculture that originated even before the recent interest in modern shrimp culture production (Kuljis and Brown, 1992). There are more than 200,000 ha of traditional, coastal brackishwater fishponds in the country and most of these ponds are used for the production of milkfish (Chanos chanos) and shrimp (P. monodon and P. indicus) (Kuljis and Brown, 1992). Shrimp farming in the country has progressed from low-density polyculture with milkfish using wild seedstock, to increasing intensities of monoculture using wild or hatchery-reared shrimp fry (Primavera, 1992). The country produced 95,816 metric tonnes of shrimps during its peak of production in 1993. However, intensification of production led to

\footnotetext{
*Author for correspondence; E-mail: cmacaipang@yahoo.com
}

environmental degradation and outbreak of diseases, such as widespread infection due to a luminescent bacterium, Vibrio harveyi, which caused a decline in shrimp production (Corre et al., 2000; Yap, 2000).

Luminescent vibriosis due to Vibrio harveyi has been reported to cause mass mortalities in shrimp, reared in hatcheries and grow-out culture ponds in the Philippines (de la Peña et al., 2001; Lavilla-Pitogo et al., 1998). $V$. harveyi is one of the 11 Vibrio species reported to be infecting cultured penaeid shrimps in Asia (LavillaPitogo, 1995), and believed to be the most dominant species of luminescent Vibrio present in shrimp ponds in the Philippines with an incidence rate of $65.5 \%$ (de la Peña et al., 2001). Heavy mortality associated with massive bacterial infection in the digestive organ of the shrimp has been observed among pond cultured P. monodon especially in the first 45 days of culture. The target organ of infection is the hepatopancreas exhibiting severe and diffuse inflammation throughout the hepatopancreas (Lavilla-Pitogo et al., 1998). Mortality in most cases exceeded $70 \%$ resulting in the termination of rearing activities and the collapse of shrimp farming industry in the Philippines (de la Peña et al., 2001).

The occurrence of luminescent vibriosis due to $V$. harveyi and the consequences of infection of this pathogen on 
the shrimp culture industry in the Philippines have resulted in the development of different techniques to control luminous bacteria in shrimp ponds. One of the techniques that had been reported to work is the "green water" culture system (Corre et al., 2000).

Available treatment schemes for luminous vibriosis. Traditionally, antibiotics have been used to control bacterial diseases in aquaculture. For example, Holmstrom et al. (2003) reported that among the shrimp farmers that they interviewed in Thailand, majority of them used antibiotics. Most of these farmers used antibiotics as prophylaxis in shrimp farms and some even used chemicals on a daily basis. There are more than ten different antibiotics being used in shrimp culture, including chloramphenicol, gentamycin, trimethoprim, tiamulin, tetracyclines, quinolones and sulfonamides. Moriarty (1999) estimated that in 1994, the use of antibiotics in shrimp farm production in Thailand reached 500-600 tonnes. In the Philippines, oxytetracycline, oxolinic acid, chloramphenicol, furazolidine, nitrofurans, erythromycin and sulfa drugs are commonly used to treat bacterial diseases (Tendencia and de la Peña, 2001). In view of the massive indiscriminate use of antibiotics in aquaculture, there have been reports of the presence of resistant strains of Vibrios to some antibiotics (Defoirdt et al., 2007). Karunasagar et al. (1994) observed massive mortality in shrimp larvae caused by $V$. harveyi strains that are resistant to cotrimoxazole, chloramphenicol, erythromycin and streptomycin. Among these antibiotics, the first two are regularly used as prophylactics. The antibiotic resistance determinants that have emerged and/or evolved in the aquaculture environments have been shown to be transmitted by horizontal gene transfer to bacteria of the terrestrial environment, including animal and human pathogens. For example, the $V$. cholerae that caused the 1992 Latin-American epidemic of cholera seemed to have acquired antibiotic resistance as a result of coming into contact with antibiotic-resistant bacteria selected through the heavy use of antibiotics in the Ecuadorian shrimp industry (Angulo, 2000). The presence of residual antibiotics in most commercial aquaculture products presents another problem with respect to human health because this can lead to an alteration of the normal human gut microflora and can generate problems of allergy and toxicity (Cabello, 2006). Given the world-wide trade in aquaculture products, health problems related to antibiotic use in aquaculture are not limited to the aquaculture-producing countries, but are also relevant to the importing countries.
It might be clear from the above that global efforts are needed to promote more judicious use of antibiotics in aquaculture and that new strategies to control pathogenic bacteria are needed to make the industry more sustainable. Currently, measures to protect aquaculture animals from luminescent vibriosis without using antibiotics are being developed and tested. Alternative biocontrol measures directed towards luminescent Vibrios have recently been developed. These are through the use of vaccination/immuno-stimulation, phage therapy, probiotics and the green water culture system (Defoirdt et al., 2007).

Stimulation of host defenses can increase resistance to infectious diseases either by triggering specific immune responses, e.g., by vaccination or by enhancing nonspecific defense systems, e.g., by immunostimulation (Sakai, 1999). Immunostimulants that are commonly used in aquaculture include live bacteria, killed bacteria, glucans, peptidoglycans and lipopolysaccharide (Smith et al., 2003). Vaccination involves the administration of weakened or dead pathogenic bacteria or viruses as well as their antigenic components, with the aim of conferring long-lasting protection through immunological memory in the host (Gudding et al., 1999). Vaccination requires primary challenge with antigen and relies on specific defense mechanisms, which are traditionally believed only to exist in vertebrates; consequently, with respect to aquaculture, vaccination would only be possible in fish and not in crustaceans (Smith et al., 2003), although a quasi-immune response has been observed in shrimp (Venegas et al., 2000). The effects of vaccination against luminescent vibriosis in several fish species have been studied by different research groups, with promising results. Elevated antibody and Vibrio inhibitory activities, induction of immune memory and significantly increased survival of experimentally infected fish have been reported (Lin et al., 2006; Arijo et al., 2005). Unfortunately, vaccination is not possible in fish larvae because of handling issues due to size and more importantly, because it is believed that fish larvae do not have a well-developed specific immunity (Vadstein, 1997). Several reports have mentioned the use of immunostimulants to control luminescent vibriosis in shrimp, resulting in increased prophenoloxidase and phenoloxidase activities and hemocyte counts, and significantly, increased survival after experimental infection with luminescent Vibrios (Marques et al., 2006; Thanardkit et al., 2002). Although, immunostimulation shows promise, there are some limitations that should be 
considered. First of all, immunostimulation might be too intense and can severely affect the host (Smith et al., 2003). Second, the response is likely to be short in duration because of the lack of memory, and hence immunostimulants will have to be administered repeatedly (Sakai, 1999). However, long-term administration of these agents likely results in the decrease of the immunostimulant effect and does not always promote disease resistance (Sakai, 1999).

Another treatment option to curb vibriosis in shrimp aquaculture is through phage therapy. In the early 1920s, bacteriophages were discovered as viral infections of bacteria, and their value for antibacterial therapy and prophylaxis was almost immediately recognized. Surprisingly, phages are recently considered as candidate therapeutics for aquaculture (Nakai and Park, 2002). Several reports described the isolation of phages of luminescent Vibrios, including lysogenic ones (Austin et al., 2003) and more recently also lytic phages (Shivu et al., 2007; Vinod et al., 2006). A major advantage of phage therapy is that non-target microbiota are not affected because the phages usually have a narrow host range (Nakai and Park, 2002). However, many phages are strain-specific rather than species-specific (Nakai and Park, 2002), so phages that will be used as biocontrol agents for luminescent vibriosis should be selected based on their capability to infect a wide range of luminescent Vibrios. Attempts to use phages to control luminescent vibriosis have only recently been reported. Shivu et al. (2007) isolated seven phages from hatchery and creek water and tested their lytic spectrum against various strains of $V$. harveyi strains that were obtained from different geographical regions. They found that the phages lysed between $15 \%$ and $69 \%$ of the strains. None of the phages was able to infect other Vibrio species. The authors concluded that shrimp hatcheries would be a good source for the isolation of phages to be used as therapeutics. Vinod et al. (2006) isolated a phage from shrimp farm water with lytic activity against all the $V$. harveyi isolates that were tested. The phage was tested both in a laboratory system and in a hatchery for its potential to protect $P$. monodon larvae. In the laboratory system, the addition of phage increased the survival of shrimp larvae that were infected with pathogenic $V$. harveyi and decreased luminescent bacterial counts after two days. In the hatchery trial, addition of the phage increased shrimp survival. Interestingly, the phage treatment performed much better than daily addition of antibiotics $(5 \mathrm{mg} / \mathrm{L}$ oxytetracyclin and $10 \mathrm{mg} / \mathrm{L}$ kanamycin).

A constraint to the use of phages as therapeutics is that phages can transfer virulence factors (Austin et al., 2003). Hence, before using bacteriophages for therapy, it is important to test, whether they carry any virulence genes and, whether they would be safe to use. A second important problem is the rapid development of resistance to phage attachment, which renders bacteria resistant to phage attack (Fischetti et al., 2006). This problem could be overcome by applying cocktails of phages or by using phage components instead of intact phage.

Next is the use of probiotics, which is a recent approach in aquaculture. The possible modes of action of probiotics include (i) production of inhibitory compounds, (ii) competition for nutrients, (iii) competition for adhesion sites in the gastrointestinal tract, (iv) enhancement of the immune response, and (v) production of essential nutrients such as vitamins and fatty acids, and enzymatic contribution to digestion (Vine et al., 2006; Verschuere et al., 2000). In addition to these beneficial actions, probiotics improve the water quality by removing toxic inorganic nitrogen or by mineralising organic matter (Verschuere et al., 2000). Another mode of action of probiotics could be specific inhibition of virulence gene expression, for instance by disrupting cell-to-cell communication (Defoirdt et al., 2007). Most investigations on probiotics as biocontrol agents to treat luminescent vibriosis have been performed using various strains of Bacillus. In one of the earliest reports, Moriarty (1998) found that the addition of a mixture of Bacillus strains that had been selected for the production of antibiotics against luminescent Vibrios resulted in healthier prawns and lower numbers of luminescent Vibrios in the pond water. Rengpipat et al. (1998) found that the addition of Bacillus strain S11 to P. monodon increased survival of the shrimp from $26 \%$ to $100 \%$ after ten days following infection with a pathogenic strain of $V$. harveyi in laboratory-scale experiments. By contrast, later experiments showed only marginal increases in the survival of challenged shrimp in farm trials following addition of the Bacillus strain to the feed (Rengpipat et al., 2003). Vaseeharan and Ramasamy (2003) showed that B. subtilis strain BT23 that was isolated from shrimp culture ponds, produced a substance which inhibited the growth of $V$. harveyi. The addition of the Bacillus strain to the culture water of shrimp larvae resulted in a significant decrease in accumulated mortality after 
15 days. In a Thai hatchery, the addition of the Bacillus mixture to the culture water significantly, improved the survival of $P$. monodon larvae. The major limitation on the use of probiotics is that in many cases they are not able to maintain themselves for a long period of time, hence, must be added regularly and at high concentrations (Vine et al., 2006), which makes this technique less cost-effective. Moreover, probiotics that were selected in vitro based on the production of inhibitory compounds might not be able to produce these compounds in vivo (Vine et al., 2006; Verschuere et al., 2000). Finally, the Vibrios might develop resistance if the production of growth-inhibitory compounds is the only mode of action, as has occurred for numerous antibiotics (Defoirdt et al., 2007). From the above, it seems to be clear that selection of probiotics needs to be performed carefully and that it might be advantageous to isolate candidate probiotics from the culture system in which they will be applied because there is a greater chance that these probionts will be able to establish themselves in the system (Verschuere et al., 2000). It is also necessary to select probiotics with more than one antagonistic characteristic or to apply a mixture of probiotics with different modes of action, to maximize the chance of success. From a commercial point of view, it would be more advantageous to determine, whether, probiotics that are already licensed for use in human or animal nutrition could be used instead of isolating new probiotics because licensing new probiotics for use in animal products is relatively expensive (Hong et al., 2005), which could be a limiting factor in the commercialization of new probiotic products.

The final approach is the use of the green water technology. The principle and the mechanisms involved in this technology is discussed in the following section.

\section{Green water system as a viable means to control luminous vibriosis in shrimp aquaculture. Green water} in ponds and other impoundments is characterised by the presence of dense microalgal populations (Moriarty, 1997). The colouration takes place usually after fertilisation by different oranic or inorganic substances (Hasan, 2007; Chen et al., 1995). The green water organisms are nutritious for different species of fish that grow together in a polyculture system (De Silva and Anderson, 1995). The fish and shrimp that grow in this kind of water consume the natural food exclusively or supplemented with commercial feeds. In addition to microalgae that are either suspended or attached to submerged substrata known as periphyton (Spataru et al., 1983), the natural food also includes macrophytes, bacteria, other microbes and zooplankton. Most of the organisms that comprise the green water ponds are photosynthetic, primarily planktonic but also macrophytic and maintain a positive oxygen balance in the water (Pekar and Olah, 1992; Schroeder et al., 1990). The use of microalgae and other planktonic microbes as aquaculture food in green water ponds has been advocated by phycologists and aquaculture nutritionists (Tacon et al., 2002; MullerFeuga, 2000; Duerr et al., 1998; Benemann, 1992).

There have been several studies on the use of green water technology to control vibriosis in tropical shrimp aquaculture. The succeeding examples were obtained from studies done in the Philippines, one of the major shrimpproducing countries in the tropics. When applied to shrimp culture as a means to control luminous vibriosis, the green water technique involves the culture of shrimp in water that was obtained from tilapia ponds, in which microalgae (such as Chlorella sp.) grow abundantly. In shrimp ponds that utilised the green water technology, Cremen et al. (2007) found a total of 103 taxa of microalgae belonging to nine different algal classes. Of these classes, the Chlorophyceae, Cyanophyceae and Bacillariophyceae constituted the great bulk of the phytoplankton population. The use of green water in shrimp ponds sustained the high density of Nannochloropsis sp., that prevented algal collapses and vibriosis. In another study, Leaño et al. (2005) identified the mycoflora of the green water culture system in shrimp ponds. They sampled pond water, tilapia gut and mucus as well as the shrimp hepatopancreas for the presence of fungi and yeasts. Results showed that high fungal loads were observed in tilapia gut, while minimal fungal populations were observed in water samples and shrimp hepatopancreas. The filamentous fungal isolates were dominated by Penicillium and Aspergillus species, while the yeast populations were dominated by Rhodotorula and Saccharomyces species. The dominance of these fungi on tilapia mucus and gut and their presence in the rearing water might play an important role in the overall mechanisms involved in the control of luminous Vibrio in the green water grow-out culture of $P$. monodon. More recently, Lio-Po et al. (2005) identified eight bacterial and 12 fungal isolates that were associated with green water and that had a promising growthinhibitory effect towards luminescent $V$. harveyi. Interestingly, the majority of the luminescent Vibrioinhibiting bacteria were isolated from tilapia skin mucus and gut. $V$. harveyi was also found to be inhibited by 
several microalgae associated with the green water. A $3-\log$ decrease in luminous Vibrio counts was observed in coculture with the microalga Leptolyngbya sp., after one day of incubation. For the algae Chaetoceros calcitrans and Nitzchia sp., an even higher growth-inhibitory effect was noticed because luminous Vibrios completely disappeared from the co-cultures after one and two days, respectively.

In the preceding studies, several organisms have been identified to be closely associated with green water system and these organisms might have a direct influence on the inhibition of luminous vibriosis. Because Chlorella sp., is one of the dominant phytoplankton species in green water system, Tendencia and dela Peña (2003) in their laboratory studies reported that $V$. harveyi was not recovered from seawater containing Chlorella after two days of incubation.

The most common fish species used in the green water culture system is the all male tilapia, Tilapia hornorum. The use of tilapia as a biomanipulator in shrimp culture was accidentally discovered by a shrimp farmer in Negros Occidental, Philippines and observed that tiger shrimp were somehow not affected by the luminous vibriosis disease when cultured in plankton-rich effluent water from tilapia ponds (Cruz et al., 2008). Monitoring of the plankton profile later identified the green algae Chlorella to be largely responsible for inhibiting the proliferation of luminous bacteria (Corre et al., 2000). Further, field trials by the NPPMCI (2000) also showed that tilapia effluent water improved water quality in shrimp culture. This novel technology, which was also shown to work with other omnivorous fish species (i.e., milkfish, Mozambique tilapia), became commonly known as the green water culture technique (NPPMCI 2000). NPPMCI (2000) reported that at a tilapia biomass of 3.0 tonnes the luminous bacterial level of the culture water is very low or could not be detected. In a laboratory study, Huervana et al. (2006) demonstrated that green water obtained from rearing tanks of tilapia, Oreochromis mossambicus has the ability to inhibit luminous vibriosis over a one-week period, and that broodstock are a better source of green water than juveniles in controlling luminous vibriosis. In tanks, Tendencia et al. (2004) demonstrated that stocking all-male tilapia at a biomass not lower than $300 \mathrm{~g} / \mathrm{m}^{3}$ efficiently inhibited the growth of luminous bacteria in shrimp (biomass $=80 \mathrm{~g} / \mathrm{m}^{3}$ ) rearing water. Further, they hypothesised two major mechanisms that may be considered for the direct inhibitory effect of tilapia on $V$. harveyi. One is the inherent property of tilapia, such as mucus and other metabolites, which could have a direct inhibitory action to $V$. harveyi, and the other is the microflora associated with tilapia culture that could have a competitive effect on $V$. harveyi. The interactions of the Chlorella sp., a major component of green water and T. hornorum in controlling luminous vibriosis were also explored (Tendencia et al., 2005). Results showed that the presence of Chlorella sp., $\left(10^{5}\right.$ cells $\left./ \mathrm{mL}\right)$ alone was not effective in the control of luminous bacteria in shrimp (biomass $=80 \mathrm{~g} / \mathrm{m}^{3}$ ) rearing water. The presence of T. hornorum alone (biomass $=500 \mathrm{~g} / \mathrm{m}^{3}$ ) was more efficient in controlling the growth of luminous bacteria than the co-existence of tilapia and Chlorella sp. Nevertheless, the presumptive Vibrio count was lowest in control tanks that had the highest shrimp survival rate, which was attributed to the presence of other microalgae such as Chaetoceros, Thalassiosira, Navicula, Nitszchia, Melosira, and Fragilaria. The inhibitory effects on luminous V.harveyi due to the presence of other microalgae confirmed the study done by Lio-Po et al. (2005). However, not only tilapia contribute to the production of greenwater in ponds and tanks. Tendencia et al. (2006) showed that the presence of commercially valued marine species such as seabass, snapper and siganid affect the growth of luminous bacteria in shrimp culture water. Results showed that luminous bacterial count of water stocked with seabass, siganid and snapper are significantly, lower than those without fish. Therefore, this study has demonstrated that seabass, siganid and snapper are alternative species for culture with shrimp to control or inhibit the growth of luminous bacteria in shrimp ponds.

Conclusion and future perspectives. Green water technology is a proven environment-friendly technology for managing luminous Vibrio disease and water quality. The results from different studies explain that the effective mechanism of the greenwater culture of shrimps in preventing outbreaks of luminous vibriosis among P. monodon juveniles in grow-out ponds can be attributed to the presence of anti-luminous Vibrio factors in the bacterial, fungal, and phytoplankton microbiota associated with this novel shrimp culture technique. In addition, the tilapia that are grown in the greenwater shed mucus that may have bactericidal effects on luminous Vibrio. Based on field experience, it also appears to be a viable technology for reducing organic matter accumulation in the sediment, promoting sustainability of culture operations. The complex factors 
controlling the composition and development of different organisms that make greenwater need to be investigated in detail for optimising the production. Thus, multidisciplinary research involving site-specific factors, management and the type of organisms that is used for culture, will lead to a better understanding of green water aquaculture and develop indicative parameters and practical monitoring tools. These can allow scientists and farmers to improve management of the water impoundments for a better production of fish and shrimp.

\section{References}

Angulo, F.J. 2000. Antimicrobial agents in aquaculture, potential impact on health. APUA Newsletter, 18: $1-6$.

Arijo, S., Rico, R., Chabrillon, M., Diaz-Rosales, P., Martinez-Manzanares, E., Balebona, M.C., Magariños, B., Toranzo, A.E., Moriñigo, M.A. 2005. Effectiveness of a divalent vaccine for sole, Solea senegalensis (Kaup), against Vibrio harveyi and Photobacterium damselae subsp. piscicida. Journal of Fish Diseases, 28: 33-38.

Austin, B., Pride, A.C., Rhodie, G.A. 2003. Association of a bacteriophage with virulence in Vibrio harveyi. Journal of Fish Diseases, 26: 55-58.

Benemann, J.R. 1992. Microalgae aquaculture feeds. Journal of Applied Phycology, 4: 233-245.

Cabello, F.C. 2006. Heavy use of prophylactic antibiotics in aquaculture: a growing problem for human and animal health and for the environment. Environmental Microbiology, 8: 1137-1144.

Chen, H., Hu, B., Charles, A.T. 1995. Chinese integrated fish farming, a comparative bioeconomic analysis. Aquaculture Research, 26: 81-94.

Cremen, M.C.M., Martinez-Goss, M.R., Corre Jr., V.L., Azanza, R.V. 2007. Phytoplankton bloom in commercial shrimp ponds using greenwater technology. Journal of Applied Phycology, 19: 615-624.

Corre Jr., V.L., Janeo, R.., Caipang, C.M., Calpe, A.T. 2000. Use of probiotics and reservoirs with green water and other tips for a successful shrimp culture. Aquaculture Asia, 2: 34-38.

Cruz, P.S., Andalecio, M.N., Bolivar, R.B., Fitzsimmons, K. 2008. Tilapia-shrimp polyculture in Negros Island, Philippines: A review. Journal of the World Aquaculture Society, 39: 713-725.

De Silva, S.S., Anderson, T.A. 1995. Fish Nutrition in Aquaculture, vol. 1, 319 pp., Chapman and Hall Aquaculture Series, Springer Science \& Business Media, London, UK.
Defoirdt, T., Boon, N., Sorgeloos, P., Verstraete, W., Bossier, P. 2007. Alternatives to antibiotics to control bacterial infections: luminescent vibriosis in aquaculture as an example. Trends in Biotechnology, 25: 472-479.

Duerr, E.O., Molnar, A., Sato, V. 1998. Cultured microalgae as aquaculture feeds. Journal of Marine Biotechnology, 6: 65-70.

Fischetti, V.A., Nelson, D., Schuch, R. 2006. Reinventing phage therapy: are the parts greater than the sum Nature Biotechnology, 24: 1508-1511.

Gudding, R., Lillehaug, A., Evensen, Ø. 1999. Recent developments in fish vaccinology. Veterinary Immunology and Immunopathology, 72: 203-212.

Hasan, M.R. 2007. Economics of Aquaculture Feeding Practices in Selected Asian Countries, FAO Fisheries Technical Paper. No. 505, 205 pp., Food and Arigulcure Organization of the United Nations, Rome, Italy.

Holmström, K., Gräslund, S., Wahlström, A., Poungshompoo, S., Bengtsson, B.-E., Kautsky, N. 2003. Antibiotic use in shrimp farming and implications for environmental impacts and human health. International Journal of Food Science and Technology, 38: 255-266.

Hong, H.A., Duc, L.H., Cutting, S.M. 2005. The use of bacterial spore formers as probiotics. FEMS Microbiological Reviews, 29: 813-835.

Huervana, F.H., de la Cruz, J.J.Y., Caipang, C.M.A. 2006. Inhibition of luminous Vibrio harveyi by 'green water' obtained from tank culture of tilapia, Oreochromis mossambicus. Acta Ichthyologica et Piscatoria, 36: 17-23.

Karunasagar, I., Pai, R., Malathi, G.R., Karunasagar, I. 1994. Mass mortality of Penaeus monodon larvae due to antibiotic-resistant Vibrio harveyi infection. Aquaculture, 128: 203-209.

Kuljis, A.M., Brown, C.L. 1992. A Market Study of Specific Pathogen Free Shrimp, Center for Tropical and Subtropical Aquaculture Publication No. 112, 154 pp., CTSA, Honolulu, Hawaii, USA.

Lavilla-Pitogo, C.R., Leaño, E.M., Paner, M.G., 1998. Mortalities of pond cultured juvenile shrimp, Penaeus monodon, associated with the dominance of luminescent Vibrio harveyi in the rearing water. Aquaculture, 164: 337-349.

Lavilla-Pitogo, C.R. 1995. Bacterial diseases of penaeid shrimps: an Asian view. In: Diseases in Asian Aquaculture II, M. Shariff, J. R. Arthur and R. P. Subasinghe (eds.), pp. 107-121, Fish Health Section, 
Asian Fisheries Society, Manila, Philippines.

Leaño, E.M., Lio-Po, G.D., Nadong, L.A., Tirado, A.C., Sadaba, R.B., Guanzon, Jr. N.G. 2005. Mycoflora of the 'green water' culture system of tiger shrimp Penaeus monodon Fabricius. Aquaculture Research, 36: 1581-1587.

Lin, J.H.Y., Chen, T.-Y., Chen, M.-S., Chen, H.E., Chou, R.-L., Chen, T.-I., Su, M.-S., Yang, H.-L. 2006. Vaccination with three inactivated pathogens of cobia (Rachycentron canadum) stimulates protective immunity. Aquaculture, 255: 125-132.

Lio-Po, G.D., Leaño, E.M., Peñaranda, M.M.D., VillaFranco, A.U., Sombito, C.D., Guanzon Jr. N.N.G. 2005. Anti-luminous vibrio factors associated with the green water grow-out culture of the tiger shrimp Penaeus monodon. Aquaculture, 250: 1-7.

Marques, A., Dhont, J., Sorgeloos, P., Bossier, P. 2006. Immunostimulatory nature of beta-glucans and baker's yeast in gnotobiotic Artemia challenge tests. Fish \& Shellfish Immunology, 20: 682-692.

Moriarty, D.J.W. 1999. Disease control in shrimp aquaculture with probiotic bacteria. In: Microbial Biosystems: New Frontiers, Proceedings of the $8^{\text {th }}$ International Symposium on Microbial Ecology, C. R. Bell, M. Brylinsky and P. Johnson-Green (eds.), pp. 237-243, Atlantic Canada Society for Microbial Ecology, Halifax, Canada.

Moriarty, D.J.W. 1998. Control of luminous Vibrio species in penaeid aquaculture ponds. Aquaculture, 164: 351-358.

Moriarty, D.J.W. 1997. The role of microorganisms in aquaculture ponds. Aquaculture, 151: 333-349.

Muller-Feuga, A. 2000. The role of microalgae in aquaculture, situation and trends. Journal of Applied Phycology, 12: 527-534.

Nakai, T., Park, S.C. 2002. Bacteriophage therapy of infectious diseases in aquaculture. Research in Microbiology, 153: 13-18.

NPPMCI, 2000. Successful Prawn Culture Management Techniques in Negros, 200 pp., Negros Prawn Producers Marketing Cooperative Inc.,Bacolod City, Negros, Occidental, Philippines.

Pekar, F., Olah, J. 1992. Carbon pathways, bioenergetic efficiencies and energy cost in fish-cum-livestock ecosystems. In: Proceedings, FAO/IPT International Workshop on Integrated Livestock-Fish Production Systems, T. K. Mukherjee, P. S. Moi, J. M. Panandam and Y. S. Yang (eds.), pp. 78-84, Kuala Lumpur, Malaysia, December 16-20, 1991, Institute of Advanced Studies, Animal Production and Health
Division, University of Malaya, Kuala Lumpur, Malaysia.

Peña, L.D. de la, Lavilla-Pitogo, C.R., Paner, M.G. 2001. Luminescent vibrios associated with mortality in pond-cultured shrimp Penaeus monodon in the Philippines, species composition. Fish Pathology, 36: 133-138.

Primavera, J.H. 1992. Marine shrimp culture in the Philippines. In: Marine Shrimp Culture, Principles and Practices, A. W. Fast and L. J. Lester (eds.), vol. 23, pp. 701-728, Elsevier, Amsterdam, The Netherlands.

Rengpipat, S., Tunyanun, A., Fast, A.W., Piyatiratitivorakul, S., Menasveta, P. 2003. Enhanced growth and resistance to Vibrio challenge in pond-reared black tiger shrimp Penaeus monodon fed on Bacillus probiotic. Diseases of Aquatic Organisms, 55: 169-173.

Rengpipat, S., Phianphak, W., Piyatiratitivorakul, S., Menasveta, P. 1998. Effects of a probiotic bacterium on black tiger shrimp Penaeus monodon survival and growth. Aquaculture, 167: 301-313.

Sakai, M. 1999. Current research status of fish immunostimulants. Aquaculture, 172: 63-92.

Schroeder, G.L., Wohlfarth, G., Alkon, A., Halevy, A., Krueger, H. 1990. The dominance of algal-based food webs in fish ponds receiving chemical fertilizers plus organic manures. Aquaculture, 86: 219-229.

Shivu, M.M., Rajeeva, B. C., Girisha, S. K., Karunasagar, I., Krohne, G. 2007. Molecular characterization of Vibrio harveyi bacteriophages isolated from aquaculture environments along the coast of India. Environmental Microbiology, 9: 322-331.

Smith, V.J., Brown, J.H., Hauton, C. 2003. Immunostimulation in crustaceans, does it really protect against infection Fish \& Shellfish Immunology, 15: 71-90.

Spataru, P., Wohlfarth, G.W., Hulata, G. 1983. Studies on the natural food of different fish species in intensively manured polyculture ponds. Aquaculture, 35: 283-298.

Tacon, A.G.J. 2003. Aquaculture production trends analysis. In: Review of the State of World Aquaculture, FAO Fisheries Circular No. 886, Rev. 2, pp. 5-29., FAO, Rome, Italy.

Tacon, A.G.J., Cody, J.J., Conquest, L.D., Divakaran, S., Forster, I.P., Decamp, O.E. 2002. Effect of culture system on the nutrition and growth performance of Pacific white shrimp Litopenaeus vannamei (Boone) fed different diets. Aquaculture 
Nutrition, 8: 121-137.

Tendencia, E.A., de la Peña, M.R., Choresca, Jr. C.H. 2006. Presence of snapper, seabass, and siganid inhibits growth of luminous bacteria in a simulated shrimp culture system. Aquaculture, 260: 54-60.

Tendencia, E.A., dela Peña, M.R., Choresca Jr. C.H. 2005. Efficiency of Chlorella sp. and Tilapia hornorum in controlling the growth of luminous bacteria in a simulated shrimp culture environment. Aquaculture, 249: 55-62.

Tendencia, E.A., dela Peña, M.R., Fermin, A.C., LioPo, G., Choresca Jr., C.H., Inui, Y. 2004. Antibacterial activity of tilapia Tilapia hornorum against Vibrio harveyi. Aquaculture, 232: 145-152.

Tendencia, E.A., de la Peña, M.R. 2003. Investigation of some components of the green water system which makes it effective in the initial control of luminous bacteria. Aquaculture, 218: 115-119.

Tendencia, E.A., de la Peña, L.D. 2001. Antibiotic resistance of bacteria from shrimp ponds. Aquaculture, 195: 193-204.

Thanardkit, P., Khunrae, P., Suphantharika, M. 2002. Glucan from spent brewer's yeast: preparation, analysis and use as a potential immunostimulant in shrimp feed. World Journal of Microbiology and Biotechnology, 18: 527-539.

Vadstein, O. 1997. The use of immunostimulation in marine larviculture, possibilities and challenges. Aquaculture, 155: 401-417.

Vaseeharan, B., Ramasamy, P. 2003. Control of pathogenic Vibrio spp. by Bacillus subtilis BT23, a possible probiotic treatment for black tiger shrimp Penaeus monodon. Letters in Applied Microbiology, 36: 83-87.

Venegas, C.A., Nonaka, L., Mushiake, K., Nishizawa, T., Muroga, K. 2000. Quasi-immune response of Penaeus japonicus to penaeid rod-shaped DNA virus (PRDV). Diseases of Aquatic Organisms, 42: 83-89.

Verschuere, L., Rombaut, G., Sorgeloos, P., Verstraete, W. 2000. Probiotic bacteria as biocontrol agents in aquaculture. Microbiology and Molecular Biology Reviews, 64: 655-671.

Vine, N.G., Leukes, W.D., Kaiser, H. 2006. Probiotics in marine larviculture. FEMS Microbiology Reviews, 30: 404-427.

Vinod, M.G., Shivu, M.M., Umesha, K.R., Rajeeva, B.C., Krohne, G., Karunasagar, I., Karunasagar, I. 2006. Isolation of Vibrio harveyi bacteriophage with a potential for biocontrol of luminous vibriosis in hatchery environments. Aquaculture, 255: 117 124.

Yap, W.G. 2000. Shrimp culture: a global overview. Bay of Bengal News (FAO/BOBP), 2: 5-12. 